\title{
Performance and carcass characteristics of Australian purebred and crossbred lambs supplemented with Rice Bran
}

\author{
Aaron Ross Flakemore ${ }^{1}$, John Roger Otto ${ }^{1}$, Bénédicte Suybeng ${ }^{1,2}$, Razaq Oladimeji Balogun ${ }^{3}$, \\ Bunmi Sherifat Malau-Aduli ${ }^{4}$, Peter David Nichols ${ }^{5}$ and Aduli Enoch Othniel Malau-Aduli ${ }^{1,6^{*}}$
}

\begin{abstract}
Background: This study examined the effects of dietary supplementation with rice bran, sire breed and gender on live animal performance and carcass characteristics in Australian crossbred and purebred Merino lambs.

Methods: Forty-eight lambs balanced by sire breed (Dorset, White Suffolk, Merino) and gender (ewe, wether) were randomly allocated into three dietary supplementation groups (Control- 24 lambs fed wheat/barley-based pellets, Low- 12 animals fed a 50/50 ratio of wheat-based/rice bran pellets, and High- 12 lambs fed rice bran pellets). The Rice bran pellets replaced $19 \%$ of the barley component of the feed. Animals were group-fed at the rate of $1000 \mathrm{~g}$ of the supplement per head per day with ad libitum access to lucerne hay as the basal diet and water. The duration of the feeding trial was 49 days with an initial 21-day adjustment period.

Results: Sire breed differences were evident for initial $(p<0.0002)$ and final $(p<0.0016)$ liveweights, hot carcass $(p<0.0030)$ and cold carcass $(p<0.0031)$ weights, as well as dressing percentage $(p<0.0078)$, fat thickness $(p<0.0467)$, yield grade $(p<0.0470)$ and rib eye area $(p<0.0022)$ with purebred Merino under-performing compared to the crossbreds. Concentrate feed conversion efficiency, costs per unit of liveweight gain and over the hooks income were comparable between treatments regardless of the observed trend where the high supplementation group tended to show lower feed intake (745.8 g/day) compared to both the control ( $939.9 \mathrm{~g} /$ day) and low supplementation groups ( $909.6 \mathrm{~g} / \mathrm{day})$. No significant differences $(p>0.05)$ were observed between treatments for live animal performance, carcass characteristics, gender and their second-order interactions.

Conclusions: Results indicate that Rice bran can be utilised as a cost-effective supplementary feed source in genetically divergent sheep over a 49-day feeding period without detrimental effects on overall live animal performance or carcass characteristics.
\end{abstract}

\section{Background}

Traditional concentrate supplementary feeds used by Australian sheep producers generally comprise wheat, barley and oats. However, these feed resources are subject to seasonal fluctuations and perturbations like drought and flooding which can impact on availability and uniformity of product quality. Likewise, increasing competition

\footnotetext{
* Correspondence: Aduli.MalauAduli@utas.edu.au

'Animal Science and Genetics, Tasmanian Institute of Agriculture, School of Land and Food, Faculty of Science, Engineering and Technology, University of Tasmania, Private Bag 54 Sandy Bay, Hobart, TAS 7001, Australia

6eterinary and Biomedical Sciences, College of Public Health, Medical and Veterinary Sciences, Division of Tropical Health and Medicine, James Cook University, Townsville, QLD 4811, Australia

Full list of author information is available at the end of the article
}

between humans and animals, animal industries, as well as increased production costs for these feeds escalate overall production costs for the sheep producer, thus impacting total on-farm profitability. Therefore, there is the need for readily available and cost-effective feed resources that are able to match or out-perform traditional supplementary feeds. These supplements should not only be cost effective, highly digestible and profitable, but also not impact negatively on animal health and wellbeing, the environment and social acceptability to the greater public [1, 2]. In this context, agro-industrial by-products such as rice bran (RB) have been put forward as viable options for ruminant production systems [3-5]. 
Rice bran, also referred to as rice pollard in Australia, is a by-product of rice milling that consists of the bran and polishings including the embryos, inner and outer bran layers, the starchy endosperm and traces of broken endosperm with relatively few hulls [4, 6, 7]. Nutritive analyses show that when stabilised, rice bran is an effective energy and fatty acid feed source constituting essential proportions of protein [6] and high content of oleic, linoleic and palmitic acids $[4,7,8]$. Rice bran is also rich in vitamins and minerals and is an exceptional source of gamma oryzanol which has both antioxidant and steroid-like properties [9].

Due to its relatively high unsaturated fatty acid content, the possibility of rice bran rancidity during storage exists $[6,10]$. This can reduce animal feed intake with potentially negative effects on animal health and wellbeing. This has been the major limiting factor regarding the use of rice bran in animal production systems. Nevertheless, research has demonstrated that stabilised rice bran is an effective dietary energy and unsaturated fatty acid source for animals such as chickens, rats and pigs with relatively minor effects on growth and performance $[10,11]$. Similarly, rice bran and its main components have demonstrated the ability to improve the plasma lipid pattern of rodents, rabbits, non-human primates and humans, reducing total plasma cholesterol and triacylglycerol concentrations and increasing high density lipoproteins [8].

A number of research articles $[1,3,5,12-15]$ have emerged evaluating rice by-products as dietary sources of nutrients in sheep production systems. However, to our current knowledge, since the late 1980's and early 1990 's research of $[6,7]$, there has been no other peerreviewed published information on sheep supplementation with rice bran in Australian prime lamb production systems. This suggests that rice by-products have become relatively neglected feed constituents in Australian sheep production systems. Moreover, this lack of updated data represents a major knowledge gap given Australia's predominance as one the world's largest sheep producing nations [16], with an average production of 647kt of paddy rice from 2000 to 2013 for domestic and export consumption [17]. Therefore, the primary objective of this study was to assess the effect of dietary rice bran supplementation on live animal performance and carcass characteristics in genetically divergent purebred and crossbred lambs currently utilised by the Australian sheep industry. The hypothesis tested was that rice bran can be used as an effective alternative supplementary feed resource for Australian sheep producers with prime lamb growth and carcass quality outcomes that are comparable to the traditional wheat-barley-based concentrate feeds.

\section{Methods}

\section{Animal ethics}

The use of animals and procedures performed in this study were all approved by the University of Tasmania Animal Ethics Committee (Permit No A0013839) and were conducted in accordance with the 1993 Tasmanian Animal Welfare Act and the 2004 Australian Code of Practice for the Care and Use of Animals for Scientific Purposes.

\section{Experimental site and animal management}

The feeding trial was conducted from $6^{\text {th }}$ May to $15^{\text {th }}$ July 2014 at the University of Tasmania Farm, Cambridge, Hobart, Tasmania, Australia. The animals were slaughtered at the Gretna Quality Meats Abattoir, Black Hills Road, Gretna, Tasmania, Australia on $17^{\text {th }}$ July 2014. Carcass dissection and meat quality parameter measurements were evaluated at Robinson Meats, Glenorchy, Hobart, Tasmania, Australia on $20^{\text {th }}$ July 2014.

The study was conducted using forty-eight (48), 8 month-old, weaned, purebred $(n=16)$ and crossbred $(n=32)$ prime lambs at an initial average body weight (BW) of $35.3 \pm 4.3 \mathrm{~kg}$. Lambs were progeny from Merino dams mated to Dorset, White Suffolk and Merino sires under the same management conditions. The experimental diets consisted of two iso-caloric and iso-nitrogenous wheat-based pellets. Table 1 shows the composition of experimental diets. Lucerne hay was used as the basal diet.

Daily rates of $1000 \mathrm{~g}$ of the supplementary feeds per lamb were offered during the three-week adjustment period as a single meal between 0700-0900 h. After the adjustment period, the experimental supplements were provided as two equal meals, as per daily allocation on

Table 1 Feed composition of the experimental diets

\begin{tabular}{lll}
\hline Ingredients \% & $\begin{array}{l}\text { Concentrate diet 1 } \\
\text { (No rice bran) }\end{array}$ & $\begin{array}{l}\text { Concentrate 2 } \\
\text { (Added rice bran) }\end{array}$ \\
\hline Wheat 12\% & 25.00 & 25.00 \\
Barley & 25.87 & - \\
Rice bran & - & 18.97 \\
GOMF & - & 10.21 \\
Mill mix & 20.17 & 10.00 \\
Lupins & 16.00 & 14.81 \\
Paddy rice & 7.26 & 15.43 \\
Limestone 37 \% & 2.09 & 1.96 \\
Ammonium sulphate & 1.25 & 1.25 \\
Salt & 1.00 & 1.00 \\
Sodium bicarbonate & 0.625 & 0.625 \\
Acid buffer & 0.625 & 0.625 \\
Bovatec 20 \% & 0.01 & 0.01 \\
\hline
\end{tabular}


weight basis per animal in each dietary treatment at 0700-0900 h and 1500-1700 h daily. All animals had ad libitum access to lucerne hay and clean fresh water throughout the duration of the feeding trial. Concentrates were provided to animals via feeding troughs attached to one side of the fence in each feeding pen, with each trough providing enough access for up to three sheep at once. Lucerne hay was provided using an elongated low level feeding trough at a size of $1.8 \mathrm{~m}$ (length) $\times 125 \mathrm{~mm}$ (height) $\times 375 \mathrm{~mm}$ (width), thus allowing all lambs to feed simultaneously. The residual concentrate feeds from each supplementary feeding group was removed and weighed the following morning before the allocation of fresh rations. Lambs were housed indoors and group-fed according to their respective dietary allocations on open slatted wooden floors. Within each group, an average area of approximately $1 \mathrm{~m}^{2}$ per animal was provided. All animals were drenched against worms using Triguard (1 g L-1 Abamectin and 22.1 g L-1 Oxfendazole) according to the manufacturer's recommendations.

\section{Experimental design and treatments}

The trial utilised a completely randomised block design employing 3 sire breeds (Merino, Dorset and White Suffolk), 3 rice bran supplementation levels (Control, Low and High) and 2 genders (ewes and wethers). The three dietary treatments consisted of: a wheat-based concentrate pellet as the control; a diet consisting of $19 \%$ rice bran replacing the barley component of the control pellet as the rice bran high diet (RBH); and a ration comprising a 50/50 combination of Control and $\mathrm{RBH}$ pelleted feeds as the rice bran low (RBL) diet. Dietary treatments consisted of 24 control animals, and 12 animals each of RBL and RBH. The feeding trial lasted 70 days, comprising a 21-day adjustment period, followed by 49 days of full supplementation.

\section{Feed analysis}

Representative samples of the experimental feeds and lucerne hay collected from each bale were used for chemical analysis. The experimental feeds were finely ground to pass through a $2 \mathrm{~mm}$ sieve using Laboratory Mill (Thomas Model 4 Wiley $^{\circ}$ Mill; Thomas Scientific). Dry matter (DM) and moisture content (MC) were determined by drying samples at $105{ }^{\circ} \mathrm{C}$ for $24 \mathrm{~h}$. Ash content was determined by combusting samples in a furnace at $600{ }^{\circ} \mathrm{C}$ for $8 \mathrm{~h}$. Neutral Detergent (NDF) and Acid Detergent (ADF) fibre contents were measured using an Ankom Fibre Analyzer (ANKOM220; ANKOM Technology, USA). Nitrogen content was determined using a Thermo Finnigan EA 1112 Series Flash Elemental Analyzer and the values multiplied by 6.25 to give the crude protein (CP) percentage. Ether extract (EE) was determined using an Ankom fat/oil extractor (ANKOMXT15; ANKOM
Technology, USA). Total digestible nutrients (\%TDN) were calculated as $\% \mathrm{TDN}=88.9-(\mathrm{ADF} \% \times 0.779)$. Metabolisable energy (ME) was calculated by converting \%TDN to digestible energy $(\mathrm{DE}[\mathrm{Mcal} / \mathrm{kg}]=\% \mathrm{TDN} \times 0.01 \times 4.4)$ which was converted as $\mathrm{ME}=(\mathrm{DE}(\mathrm{Mcal} / \mathrm{kg}) \times 0.82) \times$ 4.185. Table 2 shows the chemical compositions and energy values of the experimental and basal diets.

\section{Liveweight and feed intake}

Individual animal liveweights were recorded at weekly intervals prior to morning feeding. An electronic TruTest XR3000 livestock Walk-Over Weighing (WOW) system was used with animals standing in a relaxed position. Average daily gain was calculated as the difference between initial and final weights divided by the number of days of supplementation. Average concentrate feed intake per animal was calculated as the total feed allocated minus the residual feed divided by the number of animals for that treatment group. Feed conversion efficiency was calculated as the average daily feed intake $(\mathrm{g}) / 1000 \times 49$ [days of supplementation]/Total weight gain $(\mathrm{kg})$ over the full trial period. Concentrate cost per $\mathrm{kg}$ of live animal weight gain was calculated as concentrate feed conversion efficiency $\times(\$ / \mathrm{t} \times 1000 \mathrm{~kg})$ of supplementary feed. Feed costs $(\$ / \mathrm{kg})$ were based on an average price of pellet manufacture at \$AU 406/t, \$AU 379/t and \$AU 352/t for control, RBL and RBH diets respectively.

\section{Slaughter protocol and carcass data}

Forty lambs (minus the 8 purebred Merino ewes retained for breeding purposes) were transported to Gretna Quality Meats abattoir in the morning after the final day of the feeding trial. The animals remained in lairage for approximately $24 \mathrm{~h}$ and were slaughtered

Table 2 Proximate analysis of the experimental and basal diets

\begin{tabular}{lllll}
\hline Chemical composition (\%DM) & \multicolumn{4}{l}{ Feed components } \\
\cline { 2 - 5 } & Lucerne & $\begin{array}{l}\text { Control } \\
\text { Rice bran } \\
\text { low }\end{array}$ & $\begin{array}{l}\text { Rice bran } \\
\text { high }\end{array}$ \\
\hline MC & 10.4 & 10.2 & 8.0 & 9.8 \\
DM & 89.6 & 89.8 & 92.0 & 90.2 \\
ADF & 27.4 & 8.2 & 8.6 & 8.8 \\
NDF & 46.5 & 23.8 & 21.1 & 20.0 \\
EE & 1.1 & 2.8 & 3.4 & 4.0 \\
Ash & 5.3 & 3.4 & 6.4 & 8.1 \\
CP & 17.3 & 15.0 & 14.0 & 12.0 \\
\%TDN & 67.6 & 82.5 & 82.2 & 82.0 \\
ME (MJ/kg) & 10.2 & 12.5 & 12.4 & 12.4
\end{tabular}

Feeds were analysed on a dry matter basis; Moisture content (MC), Dry matter (DM), Neutral detergent fibre (NDF), Acid detergent fibre (ADF), Ether extract (EE) and crude protein (CP), Total digestible nutrients (\%TDN), Metabolisable energy (ME) 
adhering to Australian guidelines and practices for the humane sacrifice of livestock in commercial operations. After $24 \mathrm{~h}$ chilling, carcasses were transported in a refrigerated truck for 45 min to Robinson Meats Glenorchy for commercial cutting and carcass measurements. Measurements of hot carcass weights $(\mathrm{HCW})$ were taken after evisceration before carcass chilling. Cold carcass weights $(\mathrm{CCW})$ were recorded $24 \mathrm{~h}$ thereafter. Dressing percentage $(\%)$ was calculated as $=(\mathrm{HCW} /$ initial liveweight $\times 100$. Carcass measurements of fat thickness and body wall thickness were taken at the 12th and 13th rib interface using a GR knife over the midpoint of the Longissimus dorsi muscle perpendicular to the outside surface of the fat. Body wall thickness was measured $11 \mathrm{~cm}$ from the centre of the spine using tissue depth criteria as outlined on the GR fat knife. Rib eye area (REA) of the Longissimus dorsi muscle was evaluated using a plastic grid. Yield grade was determined as $0.4+(10 \times$ fat depth $)$. \% Boneless, Closely Trimmed Retail Cuts (BCTRC) was calculated as $49.936-(0.0848 \times$ hot carcass weight $)-(4.376 \times$ fat depth $)-(3.530 \times$ body wall thickness $)+(2.456 \times$ REA $)$. Over the hooks $(\mathrm{OTH})$ trade value was calculated as $\mathrm{HCW} \times 500 \$ / \mathrm{kg}$ divided by $100 \$$ to provide an average total dollar value per carcass for animals from each treatment group. $500 \% / \mathrm{kg}$ was the amount received per $\mathrm{kg}$ for the sale of the lambs used in this study, and is within the range for OTH prices for 2014 [18]. All values were calculated in Australian dollars.

\section{Statistical analysis}

Statistical analyses of data were performed using Statistical Analysis System [19]. Summary statistics by supplementation level, sire breed and gender were computed using PROC MEANS. The General Linear Model procedures (PROC GLM) were used for multi-trait analysis of variance fitting the fixed effects of supplementation level, sire breed and gender and their second-order interactions. Significant pairwise comparisons and mean separations set at a minimum threshold of $p<0.05$ level were carried out using Duncan's and Tukey's tests for fixed effects and interactions, respectively. Due to the group feeding design of this trial statistical evaluation of variance, feed intake, concentrate feed conversion efficiency and feed cost per unit gain were presented as group averages as per Vipond et al. [20].

\section{Results}

\section{Feed analysis}

Proximate analysis of the experimental diets is presented in Table 2. The DM content was comparable between all dietary treatments at $\sim 90 \% \mathrm{DM}$. ADF content for the lucerne at $27.4 \% \mathrm{DM}$ was up to three fold higher than that of the concentrates which were 8.2, 8.6 and 8.8 $\% \mathrm{DM}$ for the Control, RBL and RBH diets, respectively. $\mathrm{NDF}$ content was also greater for lucerne at $46.5 \% \mathrm{DM}$ compared to 23.8, 21.1 and 20.0 \%DM for the control, RBL and RBH, respectively. Ether extract and Ash contents were both greater for the $\mathrm{RBH}$ concentrate (4.0\%DM and $8.1 \% \mathrm{DM})$ compared to the Control (2.8 \%DM and 3.4\%DM), RBL (3.4 \%DM and 6.4 \%DM) and lucerne (1.1\%DM and $5.3 \% \mathrm{DM})$. The Crude Protein content of the RBH concentrate at $12.0 \% \mathrm{DM}$ was lower than all other feeds at 17.3\%DM, 15.0\%DM and 14.0 \%DM for Lucerne, Control and RBL respectively. Total digestible nutrients, digestible energy $(\mathrm{Mcal} / \mathrm{kg})$ and metabolisable energy $(\mathrm{MJ} / \mathrm{kg}$ ) were comparable between the supplementary concentrate diets at $82 \% \mathrm{TDN}, 3.6$ $\mathrm{Mcal} / \mathrm{kg}$ and $12.5 \mathrm{MJ} / \mathrm{kg}$, respectively. The basal lucerne diet was comparatively lower in \%TDN, DE and ME (67.6\%, 3.0 Mcal/kg and 10.2 MJ/kg, respectively).

\section{Rice bran supplementation}

Initial and final body weights (BW) of $35.8 \pm 0.91$ and $44.5 \pm 1.09,33.9 \pm 1.19$ and $44.5 \pm 1.8$, and $35.6 \pm 1.2$ and $43.4 \pm 1.8$ for the Control, RBL and RBH diets, respectively, were comparable between treatments $(p>0.05)$ as depicted in Table 3. Treatment differences in total and

Table 3 Means and standard errors $(\mathrm{M} \pm \mathrm{SE}$ ) of liveweight, average daily gain and dry matter intake of prime lambs supplemented with rice bran

\begin{tabular}{|c|c|c|c|c|}
\hline & Control & Rice bran low & Rice bran high & $P$ value \\
\hline Initial BW (kg) & $35.8 \pm 0.91$ & $33.9 \pm 1.19$ & $35.6 \pm 1.2$ & $0.3441^{\text {ns }}$ \\
\hline Final BW (kg) & $44.5 \pm 1.09$ & $44.5 \pm 1.84$ & $43.4 \pm 1.8$ & $0.8359^{\text {ns }}$ \\
\hline Total weight gain (kg) & $8.7 \pm 0.50$ & $10.6 \pm 1.19$ & $7.8 \pm 1.0$ & $0.1253^{\text {ns }}$ \\
\hline Av. Daily gain (g/day) & $177.3 \pm 10.24$ & $216.0 \pm 24.2$ & $159.0 \pm 19.6$ & $0.1253^{\text {ns }}$ \\
\hline Supp. Feed intake $(g / \text { day })^{a}$ & 939.9 & 909.6 & 745.8 & $0.0553^{\text {ns }}$ \\
\hline $\mathrm{FCE}^{\mathrm{b}}$ & 5.3 & 4.2 & 4.7 & $0.1523^{\text {ns }}$ \\
\hline FCPUG $^{c}$ & 2.2 & 1.7 & 1.9 & $0.0653^{\text {ns }}$ \\
\hline
\end{tabular}

${ }^{\mathrm{a}}$ Supp. Feed intake ( $\mathrm{g} / \mathrm{day}$ ) is based on the average intake per group divided by the number of animals per feeding group over the period of full supplementation (days 21-70). ${ }^{b} \mathrm{FCE}=$ Concentrate feed conversion efficiency (kg concentrate/kg BW per animal). ${ }^{\mathrm{C}} \mathrm{FCPUG}=$ Feed cost per unit gain (Concentrate cost of feed/kg live weight gain $(\$ A U / \mathrm{kg})$ per animal). Level of significance: ns not significant $(p>0.05)$ 
average daily gains were also not statistically significant $(p>0.05)$. However, in absolute terms, RBL tended to be higher $(10.58 \pm 1.19 \mathrm{~kg})$ in total weight gain over the trial period compared to the control $(8.7 \pm 0.5 \mathrm{~kg})$ and $\mathrm{RBH}$ $(7.8 \pm 1.0 \mathrm{~kg})$ diets. These equated to average daily gains of $216.0 \pm 24.2 \mathrm{~g} /$ day, $177.3 \pm 10.2 \mathrm{~g} /$ day, and $159.0 \pm$ $19.6 \mathrm{~g} /$ day for RBL, Control and RBH diets, respectively.

Lambs subjected to the RBH supplementation diet consumed less concentrate compared to the Control and RBL diets, at an average intake of $745.8 \mathrm{~g} /$ day, compared to $939.9 \mathrm{~g} /$ day and $909.6 \mathrm{~g} /$ day, respectively, although these values narrowly missed statistical significance at $p>0.0553$ (Table 3). Feed conversion efficiency (FCE) was comparable between supplementation levels at 5.3 $(\mathrm{kg} / \mathrm{kg} \mathrm{BW}), 4.2(\mathrm{~kg} / \mathrm{kg} \mathrm{BW})$, and $4.7(\mathrm{~kg} / \mathrm{kg} \mathrm{BW})$ for Control, RBL and RBH diets respectively (Table 3 ). This consecutively reflected no differences in concentrate costs per $\mathrm{kg}$ of live weight gain per animal between concentrate treatments of $\$ A U 2.2 / \mathrm{kg}, \$ A U 1.7 / \mathrm{kg}$ and $\$ A U$ $1.9 / \mathrm{kg}$ for Control, RBL and RBH respectively.

The inclusion of RB in the concentrate had no significant $(p>0.05)$ influence on any of the carcass characteristics measured in this study (Table 4). This resulted in over the hooks $(\mathrm{OTH})$ trade showing no significant differences in income returned per carcass between treatments. However, average income from RBH supplemented lambs at \$AU $97.00 \pm 7.15$ was lower per animal than both RBL (\$AU $102.15 \pm 5.57$ ) and the Control (\$AU 106.25 \pm 3.75 ). This equated to RBH differences of $-\$ A U$ S 5.15 and $-\$ A U 9.25$ compared to RBL and Control lambs respectively, and a difference of \$AU -4.10 between RBL and the Control.

\section{Sire breed}

Terminal sire breed effects (Table 5) for both initial $(p<$ $0.0002)$ and final live weights $(p<0.0016)$ showed that purebred Merino lambs were significantly lighter than Dorset and White Suffolk crosses. Merino lambs weighed $31.8 \pm 0.9 \mathrm{~kg}$ and $40.1 \pm 1.1 \mathrm{~kg}$, compared to Dorset at $37.3 \pm 1.1 \mathrm{~kg}$ and $46.8 \pm 1.6 \mathrm{~kg}$, and White Suffolk at $36.7 \pm 0.6 \mathrm{~kg}$ and $45.7 \pm 1.0 \mathrm{~kg}$ for initial and final weights, respectively. Total weight gain and average daily gains were not dependent upon the influence of terminal sire breed $(p>0.05)$. No significant $(p>0.05)$ sire breed interactions with RP supplementation level or gender were identified. Therefore, these interaction results are not presented.

Both HCW $(p<0.0030)$ and CCW $(p<0.0031)$ were significantly influenced by sire breed, with the purebred Merino showing lower weights compared to both Dorset and White Suffolk crossbred lambs. This is reflected by significant differences $(p<0.003)$ in OTH income with both Dorset (\$AU109.8 \pm 4.2$)$ and White Suffolk $(\$ A U 106.3 \pm 3.9)$ crossbreds higher in average income per carcass than purebred Merino (\$AU82.5 \pm 4.6 ). Differences in dressing $\%(p<0.0078)$, Yield grade $(p<0.0470)$ and REA $(p<0.0022)$ were also significant with Dorset and White Suffolk sired progeny having higher values in these categories compared to the Merino. The Merino also displayed significantly lower fat thickness $(p<0.0467)$ compared to other sire breeds. There was no significant difference in body wall thickness $(p>0.05)$ or GR fat score $(p>0.05)$.

\section{Sex}

There were no significant $(p>0.05)$ differences between ewe and wether lambs for liveweight, carcass traits or OTH income (Table 6). However, in absolute terms, wethers tended to produce live responses that were marginally superior to those of ewes, with slightly leaner carcasses. Interaction effects between

Table 4 Effect of treatment on carcass characteristics (Least squares means \pm SEM)

\begin{tabular}{|c|c|c|c|c|}
\hline & Control & Rice bran low & Rice bran high & $P$ value \\
\hline Pre-slaughter weight $(\mathrm{kg})^{\mathrm{a}}$ & $46.0 \pm 1.1$ & 46.0. \pm 1.8 & $44.2 \pm 2.1$ & $0.3150^{\text {ns }}$ \\
\hline $\mathrm{HCW}(\mathrm{kg})^{\mathrm{b}}$ & $21.3 \pm 0.8$ & $20.4 \pm 1.1$ & $19.4 \pm 1.4$ & $0.3609^{\text {ns }}$ \\
\hline $\operatorname{CCW}(\mathrm{kg})^{\mathrm{c}}$ & $21.0 \pm 0.7$ & $20.1 \pm 1.1$ & $19.1 \pm 1.4$ & $0.3417^{\text {ns }}$ \\
\hline Dressing percentage (\%) & $46.2 \pm 1.2$ & $44.4 \pm 1.6$ & $43.5 \pm 1.5$ & $0.6819^{\text {ns }}$ \\
\hline Fat thickness (mm) & $4.5 \pm 0.3$ & $4.3 \pm 0.5$ & $3.8 \pm 0.5$ & $0.1602^{\text {ns }}$ \\
\hline Body wall thickness (mm) & $15.2 \pm 0.7$ & $17.1 \pm 1.1$ & $14.2 \pm 1.3$ & $0.1639^{\text {ns }}$ \\
\hline GR fat score (1-5) & $3.5 \pm 0.2$ & $4.0 \pm 0.3$ & $3.1 \pm 0.3$ & $0.0912^{\text {ns }}$ \\
\hline Yield grade & $2.2 \pm 0.1$ & $2.1 \pm 0.2$ & $1.9 \pm 0.2$ & $0.1596^{\mathrm{ns}}$ \\
\hline Rib eye area $\left(\mathrm{cm}^{2}\right)$ & $15.0 \pm 0.5$ & $15.3 \pm 0.8$ & $14.5 \pm 0.9$ & $0.5246^{\mathrm{ns}}$ \\
\hline $\mathrm{BCTRC}^{\mathrm{d}}$ & $48.8 \pm 0.2$ & $48.8 \pm 0.3$ & $49.2 \pm 0.4$ & $0.4228^{\text {ns }}$ \\
\hline OTH trade $(\$ A U)^{e}$ & $106.3 \pm 3.8$ & $102.2 \pm 5.6$ & $97.0 \pm 7.2$ & $0.4398^{\text {ns }}$ \\
\hline
\end{tabular}

${ }^{\mathrm{a}}$ Pre-slaughter weight is the weight of animals (minus Merino ewes) prior to transport for slaughter. ${ }^{\mathrm{b}} \mathrm{HCW}=\mathrm{Hot}$ carcass weight. ${ }^{\mathrm{c}} \mathrm{CCW}=\mathrm{Cold}$ carcass weight. ${ }^{d}$ BCTRC\% = Boneless, Closely Trimmed Retail Cuts. ${ }^{e} \mathrm{OTH}=$ Over the hooks trade (this was based on 500 CAU return per kg of HCW). Level of significance: ns not significant $(p>0.05)$ 
Table 5 Means and standard errors $(M \pm S E)$ of live animal performance and carcass characteristics of prime lamb progeny from different sire breeds

\begin{tabular}{|c|c|c|c|c|}
\hline & Dorset & White Suffolk & Merino & $P$ value \\
\hline Initial BW (kg) & $37.3 \pm 1.1$ & $36.7 \pm 0.6$ & $31.8 \pm 0.9$ & $0.0002^{* * *}$ \\
\hline Final BW (kg) & $46.8 \pm 1.6$ & $45.7 \pm 1.0$ & $40.1 \pm 1.1$ & $0.0016^{* *}$ \\
\hline Total weight gain (kg) & $9.5 \pm 1.0$ & $9.0 \pm 0.7$ & $8.3 \pm 0.7$ & $0.4418^{\mathrm{ns}}$ \\
\hline Av. Daily gain (g) & $194.5 \pm 20.3$ & $183.7 \pm 14.5$ & $169.0 \pm 14.8$ & $0.4418^{\text {ns }}$ \\
\hline Pre-slaughter weight $(\mathrm{kg})^{c}$ & $47.0 \pm 1.6$ & $45.7 \pm 1.0$ & $42.2 \pm 1.78$ & $0.0540^{\mathrm{ns}}$ \\
\hline $\mathrm{HCW}(\mathrm{kg})^{\mathrm{d}}$ & $22.0 \pm 0.9^{a}$ & $21.3 \pm 0.8^{\mathrm{a}}$ & $16.5 \pm 0.9^{b}$ & $0.0030^{* *}$ \\
\hline CCW $(\mathrm{kg})^{\mathrm{d}}$ & $21.7 \pm 0.9^{a}$ & $21.0 \pm 0.8^{a}$ & $16.2 \pm 0.9^{b}$ & $0.0031^{* *}$ \\
\hline Dressing percentage (\%) & $46.7 \pm 0.8^{a}$ & $46.3 \pm 1.2^{\mathrm{a}}$ & $39.2 \pm 1.7^{b}$ & $0.0078^{*}$ \\
\hline Fat thickness (mm) & $4.7 \pm 0.4^{a}$ & $4.3 \pm 0.3^{a}$ & $3.3 \pm 0.5^{b}$ & $0.0467^{*}$ \\
\hline Body wall thickness (mm) & $16.1 \pm 1.1$ & $15.6 \pm 0.7$ & $13.8 \pm 1.2$ & $0.2648^{\mathrm{ns}}$ \\
\hline GR fat score (1-5) & $3.7 \pm 0.3$ & $3.6 \pm 0.2$ & $3.1 \pm 0.3$ & $0.3013^{\mathrm{ns}}$ \\
\hline Yield grade & $2.3 \pm 0.5^{a}$ & $2.1 \pm 0.1^{\mathrm{a}}$ & $1.7 \pm 0.8^{b}$ & $0.0470^{*}$ \\
\hline Rib eye area $\left(\mathrm{cm}^{2}\right)$ & $15.6 \pm 0.5^{\mathrm{a}}$ & $15.5 \pm 0.5^{\mathrm{a}}$ & $12.3 \pm 0.8^{b}$ & $0.0022^{* *}$ \\
\hline BCTRC \% ${ }^{e}$ & $48.7 \pm 0.2$ & $49.0 \pm 0.2$ & $49.0 \pm 0.3$ & $0.5937^{\text {ns }}$ \\
\hline $\mathrm{OTH}^{\mathrm{f}}$ & $109.8 \pm 4.2^{\mathrm{a}}$ & $106.3 \pm 3.9^{\mathrm{a}}$ & $82.5 \pm 4.6^{b}$ & $0.0030^{* *}$ \\
\hline
\end{tabular}

${ }^{C}$ Pre-slaughter weight is the weight of animals (minus Merino ewes) prior to transport for slaughter. ${ }^{\mathrm{d}} \mathrm{HCW}=\mathrm{Hot}$ carcass weight. ${ }^{\mathrm{e}} \mathrm{CCW}=\mathrm{Cold}$ carcass weight. ${ }_{\mathrm{B}}^{\mathrm{B} C T R C} \%=$ Boneless, Closely Trimmed Retail Cuts. ${ }^{\mathrm{f}} \mathrm{OTH}=$ Over the hooks trade (this was based on $500 \mathrm{C}$ AU return per kg of HCW). Level of significance: ns not significant $(p>0.05),{ }^{*}$ significant $(p<0.05),{ }^{* *}$ highly significant $(p<0.01)$, and ${ }^{* * *}$ very highly significant $(p<0.001)$. Different superscripts indicate significant differences within each row $(p<0.05)$

Table 6 Means and standard errors $(\mathrm{M} \pm \mathrm{SE})$ of live animal performance and carcass characteristics of ewe and wether prime lambs

\begin{tabular}{|c|c|c|c|}
\hline & Ewe & Wether & $P$ value \\
\hline Initial BW (kg) & $34.7 \pm 0.89$ & $35.9 \pm 0.86$ & $0.4320 \mathrm{~ns}$ \\
\hline Final BW (kg) & $42.9 \pm 1.1$ & $45.5 \pm 1.18$ & $0.1336 \mathrm{~ns}$ \\
\hline Total weight gain (kg) & $8.2 \pm 0.5$ & $9.8 \pm 0.75$ & $0.1202 \mathrm{~ns}$ \\
\hline Av. Daily gain (g) & $167.5 \pm 11.0$ & $197.3 \pm 15.29$ & $0.1202 \mathrm{~ns}$ \\
\hline Pre-slaughter weight $(\mathrm{kg})^{\mathrm{a}}$ & $45.5 \pm 1.2$ & $45.5 \pm 1.18$ & $0.3318 \mathrm{~ns}$ \\
\hline $\mathrm{HCW}(\mathrm{kg})^{\mathrm{b}}$ & $21.0 \pm 0.7$ & $20.3 \pm 0.87$ & $0.3662 \mathrm{~ns}$ \\
\hline $\mathrm{CCW}(\mathrm{kg})^{\mathrm{C}}$ & $20.7 \pm 0.7$ & $20.0 \pm 0.87$ & $0.3738 \mathrm{~ns}$ \\
\hline Dressing percentage (\%) & $46.1 \pm 0.9$ & $44.4 \pm 1.19$ & $0.8343 \mathrm{~ns}$ \\
\hline Fat thickness (mm) & $4.7 \pm 0.3$ & $4.0 \pm 0.27$ & 0.3389 ns \\
\hline Body wall thickness (mm) & $15.9 \pm 1.1$ & $15.1 \pm 0.62$ & $0.6601 \mathrm{~ns}$ \\
\hline GR fat score $(1-5)$ & $3.6 \pm 0.3$ & $3.5 \pm 0.16$ & $0.6415 \mathrm{~ns}$ \\
\hline Yield grade & $2.2 \pm 0.1$ & $2.0 \pm 0.10$ & $0.3385 \mathrm{~ns}$ \\
\hline Rib eye area $(\mathrm{cm} 2)$ & $15.2 \pm 0.5$ & $14.8 \pm 0.51$ & 0.4659 ns \\
\hline BCTRC $\%^{d}$ & $48.8 \pm 0.2$ & $49.0 \pm 0.17$ & $0.6550 \mathrm{~ns}$ \\
\hline $\mathrm{OTH}^{\mathrm{e}}$ & $104.9 \pm 3.4$ & $101.6 \pm 4.3$ & $0.3662 \mathrm{~ns}$ \\
\hline
\end{tabular}

apre-slaughter weight is the weight of animals (minus Merino ewes) prior to transport for slaughter. ${ }^{b} \mathrm{HCW}=$ Hot carcass weight. ${ }^{\mathrm{c}} \mathrm{CCW}=$ Cold carcass weight. ${ }^{\mathrm{d} B C T R C} \%=$ Boneless, Closely Trimmed Retail Cuts. ${ }^{\mathrm{e}} \mathrm{OTH}=$ Over the hooks trade (this was based on $500 \mathrm{C} \mathrm{AU}$ return per $\mathrm{kg}$ of $\mathrm{HCW}$ ). Level of significance: ns not significant $(p>0.05)$ gender and supplementation level were all non-significant, hence not presented in tables.

\section{Discussion}

\section{Proximate analysis of feeds}

The $89.6 \% \mathrm{DM}, 17.3 \% \mathrm{CP}$ and 10.2 ME contents of the lucerne hay used as the basal diet in this study were similar to the $87 \% \mathrm{DM}, 18 \% \mathrm{CP}$ and $9(\mathrm{MJ} / \mathrm{kg})$ averages for Australian lucerne hay [21]. The CP content of the basal diet was in excess of the $7 \%$ CP content required in feeds to support acceptable rumen microbial activity and the maintenance requirement of the host ruminant [22]. The high ADF content of the lucerne reduced the \%TDN and energy values compared to the concentrates. The ME value of $10.2 \mathrm{MJ} / \mathrm{kg}$ in the basal lucerne hay was lower than the $12 \mathrm{MJ} / \mathrm{kg}$ required in a ration for ideal growth rates [23]. This indicates that supplementary feeding was required, and that any observed effects on growth performance were more likely a response to the addition of the concentrate supplementary feeds.

The DM, CP and ME values for RBL and RBH were comparable to the averages for Australian RB reported by Hinton [21] and Warren and Farrell [7]. The CP contents of both RB containing diets used in the present study were in excess of the $7 \% \mathrm{CP}$ requirement for ruminant maintenance. $\mathrm{CP}$ was higher than those of Nega and Melaku [14] and Asmare et al. [3] at $11 \%$ and $7.8 \%$ respectively, but comparable to the $15 \%$ and $13 \%$ in the RB diets of Tabeidian and Sadeghi [5]. The RB diets in 
the present study contained less than the $25.6 \% \mathrm{NDF}$, $12.2 \%$ ADF, $10.8 \%$ Ash and $22 \%$ EE values reported by Warren and Farrell [7]. The discrepancies are reflective of the report of Warren and Farrell [7] that despite the quality of Australian produced rice bran being reasonably uniform, differences in nutritive value are mainly due to variations in seasonal conditions and cultivar variety.

\section{Rice bran supplementation}

The non-significant differences in animal performance and carcass characteristics associated with rice bran supplementation supports our tested hypothesis. This confirms that rice bran can be used as an effective supplement at levels of up to $19 \%$ without impeding the ability of lambs to achieve a targeted $45 \mathrm{~kg}$ liveweight, ideal for the Australian domestic market from an initial $35 \mathrm{~kg}$ liveweight when fed over a 49-day full dietary finishing period.

The results in this study compare to those previously reported by Tabeidian and Sadeghi [5] showing no significant differences in overall live animal performance with rice bran replacing barley at levels of up to $30 \%$ in a concentrate diet fed to uncastrated male Afshari lambs over a period of 85 days. However, whilst the initial liveweights herein were comparable to those of Tabeidian and Sadehi [5], the final, average daily and total weight gains were extensively lower. This may be due to a combination of factors between studies; breed, gender, age, feeding duration and management conditions. The average daily gains are similar to those reported by Hogan et al. [6] in which Border Leicester $\times$ Merino $\times$ Dorset ewe and wether lambs administered rice bran oil at $10 \%$ inclusion level achieved growth rates between 100-150 g/day under Australian production systems. Similarly, the improved liveweight gains for the RBL treatment compared to the Control and RBH diet in this study agree with the findings of Asmare et al. [3], Nega and Melaku [14] and SalinasChavira et al. [24] demonstrating that mixed ration formulations with rice by-products improved and/or maintained live animal performance attributes in sheep.

Feed intake declined with rice bran at an inclusion level of $19 \%$ in this study. This was unexpected given previous findings that total feed intake (hay + concentrate) (at $\sim 1500 \mathrm{~g} /$ day) was generally unaffected when lambs were fed rations containing up to $30 \%$ rice bran in the finishing diet [5], or in dairy goats fed $20 \%$ rice bran [25]. Likewise, Hogan et al. [6] demonstrated that Australian extracted rice bran oil at levels of $10 \%$ inclusion did not generally affect feed intake of Australian crossbred sheep averaging $1 \mathrm{~kg} /$ day. However, the decline in feed intake in this study agrees with the work of Tabeidian and Sadeghi [5] demonstrating that total feed intake (concentrate + hay) declined in sheep fed concentrates containing rice bran at levels of $45 \%$ (1330 g/day) and $60 \%$ (1150 g/day) compared to $0 \%$ (1450 g/day). Likewise, Bhatt et al. [12] showed that in Malpura lambs offered $\sim 1500 \mathrm{~g} /$ day, the concentrate intake significantly declined from $550 \mathrm{~g} /$ day to $472 \mathrm{~g} /$ day when $40 \mathrm{~g} / \mathrm{kg}$ of rice bran oil was added.

Numerous mechanisms for the occurrence of reduced feed intake associated with RB had been proposed. Asmare et al. [3] and Cutrim et al. [13] advocated that reduced intakes with rice bran supplemented sheep are due to high NDF and ADF contents of RB. Whereas Park et al. [25] suggested that reduced feed intake was associated with lower production of acetate and ß-hydroxy-butyrate in the rumen or due to increased uptake of dietary long-chain fatty acids, thus inhibiting de novo fatty acid synthesis. Garg et al. [26] outlined that concentrates containing high levels of rice bran affected the digestibility of fat, protein and ADF in the rumen. Both Boucque and Fiems [4] and Nega and Melaku [14] suggested that elevated mineral content, namely increased levels of silica, was the main limiting factor affecting dietary intake of rice bran in sheep when fed in large amounts. The diets used in this study showed comparable levels of CP, EE, NDF and ADF between treatments. Therefore, it is likely that the major factor that affected dietary intake was the relatively high NDF and mineral contents of the RBH diet compared to the other treatments [13].

The similar carcass characteristics between treatments in this study demonstrates that rice bran can be used as an effective alternative supplementary feed source for Australian sheep producers. This overall finding again supports the tested hypothesis. However, the minor differences in body wall thickness between treatments corresponded to differences in GR fat score. Nevertheless, given that all dietary treatments produced sheep with carcass characteristics that meet the majority of Australian domestic and export market specifications for sheep meat [27], it is unlikely that any differences in GR fat class would translate into substantial differences in potential sale value.

Previously published investigations assessing the impact of rice bran on carcass characteristics have demonstrated comparable results to those presented herein. Tabeidian and Sadeghi [5] showed that RB at levels of up to $65 \%$ in the concentrate diet of sheep had no effect on slaughter weight or HCW. However, they reported that a significant increase in dressing percentage occurred when sheep were supplemented with RB at $15 \%$ compared to the control. These authors could not attribute this observation to any particular causal effect. However, given that only three lambs from each dietary group were slaughtered in their trial, it is our opinion that this could have been a response to individual variation between experimental groups. Nevertheless, no 
differences in dressing percentage between RB levels or the control were observed when sheep were supplemented with RB at levels of 30, 45 and $60 \%$. This was despite significant poorer animal performance particularly at the $45 \%$ and $60 \%$ inclusion level. Similar to our results, Salinas-Chavira et al. [24] showed no significant differences in Longissimus dorsi muscle area between treatments with $18 \%$ rice polishings and tallow compared to the basal diet fed as a supplement to Pelibuey lambs. In another study, Bhatt et al. [12] showed similar dressing yields, loin eye areas and body fat distributions between $4 \%$ RBO supplemented sheep compared to a concentrate control diet, but their study was marked by significantly lower $\mathrm{HCW}$ between treatments.

Studies observing reduced feed intakes with minimal effects on live animal performance have led to recommendations that the application of rice by-products in sheep diets may be more advantageous from an economic viewpoint $[1,13]$. The reduced feed intakes between treatments, with no differences in feed requirements, or costs per $\mathrm{kg}$ of live weight gain between treatments herein concur with this line of thinking. However, the possible variable income between animals of differing treatments, whilst not significant would show considerable differences in overall flock income. The extent of cost-benefit analysis in feed conversion ratio and feed per $\mathrm{kg}$ live weight gain are dependent upon price differentiations between feed sources, rice bran quality and composition, application rate, supplement intake, and OTH prices offered at the time of sale. Other management input considerations such as time, labour, infrastructure costs and total on-farm profitability margins should also be considered.

\section{Sire breed}

Results indicate that the greatest variations in animal performance for this study are derived between sire breeds. Similarly, the lack of significant interactions between sire breed and gender, and sire breed and supplementation level indicates that genetic performance through the influence of sire breed is maintained regardless of these influences. This outcome is in line with previous research findings that the Merino is a slower growing, leaner sheep breed, taking longer to reach maturity and therefore market slaughter weights [28-31]. This is particularly evident when compared to other breeds and $1^{\text {st }}$ cross lambs currently used in Australian sheep production systems.

The lack of significant differences in average daily gains between sire breeds in this study is comparable to Holman et al. [32], who also showed no significant differences between these breeds and crosses when trialling Spirulina supplementation. It is established that the Merino has a genetic predisposition for increased wool growth compared to both Dorset and White Suffolk, both with biases for growth and muscling [30, 33]. Therefore, it can be reasoned that similarities in gains between breeds was primarily a product of combined effects of wool production and body weight increases in the Merino. In comparison, increases in BW for lambs from Dorset and White Suffolk $1^{\text {st }}$-crosses were primarily a reflection of the genetic predispositions of these sire breeds for growth.

When purebred Merino lambs are slaughtered at the same age as other breeds, notably $1^{\text {st }}$ cross lambs sired from established meat breeds, the Merino exhibits significantly poorer carcass performance characteristics $[28,30,33]$. This consequentially manifests in lower rates of returns for straight Merino carcasses. This further indicates that nutrient partitioning between animals based upon genetic variation and predispositions for production traits are prevalent amongst the breeds utilised in this study.

\section{Sex}

Similar performance between ewes and wethers regardless of nutritional or sire breed influences indicates that whilst male lambs are inherently larger and leaner, castration reduced male hormonal effects thereby resulting in wethers showing growth and carcass compositions comparable to those of ewes [34, 35]. This provides marketing options for producers regarding the use and management of ewe and wether lambs in their flock.

\section{Conclusions}

This study is of importance as it is, as far as we are aware, the first in over two decades to evaluate the effects of rice bran supplementation for lambs used by the Australian sheep industry. Additionally, the results of the study are of importance as they have further added to current knowledge of the impact of $\mathrm{RB}$ as a supplementary feed source on the productive performance of purebred and crossbred sheep. In summary, supplementation of prime lambs with RB at an inclusion level of $19 \%$ to replace barley in a concentrate diet did not negate live animal performance or carcass characteristics over a 49-day finishing period. Furthermore, RB was shown as an effective supplementary feed in terms of costs to the prime lamb producer. Purebred Merino lambs at the same age and management conditions as crossbreds demonstrated comparatively lower live performance and carcass characteristics. Production performance was similar between ewes and wethers. Put together, these results will enable sheep producers to make informed management decisions regarding the utilisation of $\mathrm{RB}$ in their flock for finishing prime lambs. 


\section{Competing interests}

The authors declare that they have no competing interests.

\section{Authors' contributions}

This work was carried out in collaboration between all authors. Authors ARF, JRO and BS ran the feeding trial, laboratory analyses, collected experimental samples, performed carcass and feed analysis and ARF wrote the first draft of the manuscript as part of his PhD project. Authors BSMA, PDN and AEOMA contributed in the reading and making needed changes to the draft manuscript. Author AEOMA conceived the research idea, wrote the funding grant, experimental design, read and made final changes to the final manuscript as a research article. All authors read and approved the final manuscript.

\section{Acknowledgements}

The authors gratefully acknowledge the contribution by CopRice Feeds, Cobden, Victoria, Australia for collaborative research support of producing the experimental pellets to specification. We acknowledge with gratitude, the University of Tasmania and the Australian Postgraduate Award of the Commonwealth Government of Australia for awarding PhD research scholarships to Aaron Ross Flakemore and John Roger Otto.

\section{Author details}

${ }^{1}$ Animal Science and Genetics, Tasmanian Institute of Agriculture, School of Land and Food, Faculty of Science, Engineering and Technology, University of Tasmania, Private Bag 54 Sandy Bay, Hobart, TAS 7001, Australia. ${ }^{2}$ Institut National Supérieur des Sciences Agronomiques de l'alimentation et de l'environnmente (AGROSUP), 26 Bd du Docteur Petitjean, BP 8799921079 Dijon Cedex, France. ${ }^{3}$ CopRice Feeds, PO Box 104, Cobden, VIC 3266, Australia. ${ }^{4}$ College of Medicine and Dentistry, Division of Tropical Health and Medicine, James Cook University, Townsville, QLD 4811, Australia. ${ }^{5}$ CSIRO Food and Nutrition, Oceans and Atmosphere Flagships, Hobart, TAS 7001, Australia. ${ }^{G}$ Veterinary and Biomedical Sciences, College of Public Health, Medical and Veterinary Sciences, Division of Tropical Health and Medicine, James Cook University, Townsville, QLD 4811, Australia.

Received: 13 March 2015 Accepted: 23 September 2015 Published online: 01 October 2015

\section{References}

1. Muhammad N, Maigandi SA, Hassan WA, Daneji Al. Growth performance and economics of sheep production with varying levels of rice milling waste. Sokoto J Vet Sci. 2008;7(1):59-64.

2. Smith $\mathrm{OB}$, Osafo ELK, Adegbola AA. Studies on the feeding value of Agro-industrial by-products-Strategies for improving the utilization of cocoa-pod-based diets by ruminants. Anim Feed Sci Technol. 1988;20(3):189-201.

3. Asmare B, Melaku S, Peters KJ. Supplementation of Farta sheep fed hay with graded levels of concentrate mix consisting of noug seed meal and rice bran. Trop Anim Health Prod. 2010;42(7):1345-52.

4. Boucque CV, Fiems LO. Vegetable by-products of Agro-industrial origin. Livestock Prod Sci. 1988;19(1-2):97-135.

5. Tabeidian SA, Sadeghi G. Effect of replacing barley with rice bran in finishing diet on productive performance and carcass characteristics of Afshari lambs. Trop Anim Health Prod. 2009:41(5):791-6.

6. Hogan JP, Cook LJ, Davis P. The nutritional-value of rice pollard for sheep. Aust J Agric Res. 1988;39(3):525-31.

7. Warren BE, Farrell DJ. The nutritive-value of full-fat and defatted Australian rice bran.1. Chemical composition. Anim Feed Sci Technol. 1990;27(3):219-28.

8. Cicero AFG, Derosa G. Rice bran and its main components: potential role in the management of coronary risk factors. Curr Top Nutraceut Res. 2005;3(1):29-46.

9. Saunders RM. The properties of rice bran as a foodstuff. Cereal Foods World. 1990;35(7):632-6.

10. Warren BE, Farrell DJ. The nutritive-value of full-fat and defatted rice bran.2. Growth studies with chickens, rats and pigs. Anim Feed Sci Technol. 1990;27(3):229-46.

11. Srichai Y, Balnave D. Egg weight responses to dietary supplementation with sunflower oil and rice pollard. Aust J Agric Res. 1981;32(1):183-8.
12. Bhatt RS, Karim SA, Sahoo A, Shinde AK. Growth Performance of Lambs Fed Diet Supplemented with Rice Bran Oil as Such or as Calcium Soap. Asian-Austral J Anim Sci. 2013;26(6):812-9.

13. Cutrim DO, Alves KS, Sampaio Oliveira LR, dos Santos RDC, da Mata VJ V, Do Carmo DM, et al. Elephant grass, sugarcane, and rice bran in diets for confined sheep. Trop Anim Health Prod. 2012;44(8):1855-63.

14. Nega A, Melaku S. Feed intake, digestibility and body weight change in Farta sheep fed hay supplemented with rice bran and/or noug seed (Guizotia abyssinica) meal. Trop Anim Health Prod. 2009;41(4):507-15.

15. Salinas-Chavira J, Perez JA, Rosales JA, Hernandez EA, La O. Effect of increasing levels of rice polishings on ruminal dry matter degradability and productive performance of fattening sheep. Cuban J Agr Sci. 2013;47(4):375-80

16. MLA. Fast facts: Australia's sheep meat industry. North Sydney, New South Wales, Australia: Meat and Livestock Australia; 2013.

17. ABARES. Agricultural commodity statistics. Canberra, Australia: Australian Bureau of Agricultural and Resource Economics and Sciences, Australian Capital Territory; 2013.

18. MLA. Market reports and prices. Meat and Livestock Australia Limited. www.mla.com.au/Prices-and-markets/Market-reports-and-prices. 2014. Accessed 26 Sept. 2015.

19. SAS. Statistical Analysis System. Cary, NC, USA: SAS Institute, version 92; 2009.

20. Vipond JE, Lewis M, Horgan G, Noble RC. Malt distillers grains as a component of diets for ewes and lambs and its effects on carcass tissue lipid-composition. Anim Feed Sci Technol. 1995;54(1-4):65-79.

21. Hinton DG. Supplementary feeding of sheep and beef cattle. Secondth ed. Melbourne, Australia: Landlinks Press; 2007. p. 104.

22. McDonald. Animal Nutrition. 5th ed. Harlow, Essex, England; New York: Longman Scientific \& Technical; J. Wiley; 1995. p. 607.

23. Easton W, Donlevy JW. Opportunity lot feeding of lambs. Australia: Victoria Dep. of Agriculture, Agmedia; 1994. p. 67.

24. Salinas-Chavira J, Guerrero VI, Robles CA, Montano-Gomez MF, Montanez-Valdez OD. Effect of tallow and rice polishings in feedlot rations on growth and carcass characteristics of lambs. J Appl Anim Res. 2008;34(1):45-8.

25. Park JK, Kwon EG, Kim CH. Effects of increasing supplementation levels of rice bran on milk production and fatty acid composition of milk in Saanen dairy goats. Anim Prod Sci. 2013;53(5):413-8.

26. Garg AK, Singh P, Malik R, Agrawal DK. Effect of replacing maize grain with de-oiled rice bran on intake and utilisation of nutrients in adult ewes. Small Rum Res. 2004:52(1-2):75-9.

27. AWI/MLA. Making More from Sheep. Module 3. Market Focused Lamb and Sheepmeat Production. In: Making More from Sheep. Australian Wool Innovation and Meat \& Livestock Australia. 2008. www.makingmore fromsheep.com.au. Accessed 26 Sept. 2015.

28. Fogarty NM, Safari E, Taylor PJ, Murray W. Genetic parameters for meat quality and carcass traits and their correlation with wool traits in Australian Merino sheep. Aust J Agric Res. 2003;54(7):715-22.

29. Ponnampalam EN, Butler KL, Hopkins DL, Kerr MG, Dunshea FR, Warner RD. Genotype and age effects on sheep meat production. 5. Lean meat and fat content in the carcasses of Australian sheep genotypes at 20-, 30- and 40-kg carcass weights. Aust J Exp Agric. 2008;48(6-7):893-7.

30. Warner RD, Pethick DW, Greenwood PL, Ponnampalam EN, Banks RG, Hopkins DL. Unravelling the complex interactions between genetics, animal age and nutrition as they impact on tissue deposition, muscle characteristics and quality of Australian sheep meat. Aust J Exp Agric. 2007;47(10):1229-38.

31. Warner RD, Jacob RH, Edwards JEH, McDonagh M, Pearce K, Geesink G, et al. Quality of lamb meat from the Information Nucleus Flock. Anim Prod Sci. 2010;50(11-12):1123-34.

32. Holman B, Kashani A, Malau-Aduli AEO. Growth and body conformation responses of genetically divergent Australian sheep to Spirulina (Arthrospira platensis) supplementation. American J Exp Agric. 2012;2:160-73.

33. Scales GH, Bray AR, Baird DB, O'Connell D, Knight TL. Effect of sire breed on growth, carcass, and wool characteristics of lambs born to Merino ewes in New Zealand. NZ J Agric Res. 2000;43(1):93-100.

34. Geesink, Zerley. Chapter 16: Meat Production from, International Sheep and Wool Handbook, New Edition. Nottingham Chicago: Cottle Nottingham University Press Independent Publishers Group Distributor; 2010.

35. Warriss PD. Meat science: an introductory text. Warriss PD, editor. Oxfordshire, UK: CAB International; 2009. p. 234. doi:10.1079/9780851994246.0000. 